\title{
Effects of the Mycoparasite Sphaerellopsis filum on Overwintering Survival of Stem Rust in Perennial Ryegrass
}

T. C. Gordon, Oregon State University Department of Botany and Plant Pathology; and W. F. Pfender, United States Department of Agriculture-Agricultural Research Service Forage Seed and Cereal Research Unit, and Oregon State University Department of Botany and Plant Pathology, Corvallis 97331

\begin{abstract}
Gordon, T. C., and Pfender, W. F. 2012. Effects of the mycoparasite Sphaerellopsis filum on overwintering survival of stem rust in perennial ryegrass. Plant Dis. 96:1471-1481.

Sphaerellopsis filum is a mycoparasite of Puccinia graminis subsp. graminicola, a rust fungus that causes widespread crop damage on perennial ryegrass grown for seed. In observations taken over the winter months, $S$. filum was found naturally colonizing $2 \%$ of $P$. graminis subsp. graminicola uredinia on first-year plantings and $25 \%$ of the uredinia on second-year plantings of perennial ryegrass. In controlled experiments conducted in glasshouses and growth chambers, $S$. filum applied to rust-inoculated plants reduced the lifetime spore production of $P$. graminis subsp. graminicola pustules by half, from 39,000 to 18,000 spores/pustule . Mist duration, temperature, and P. graminis subsp. graminicola pustule age at the time of $S$. filum inoculation had significant effects on the proportion of $P$. graminis subsp. graminicola pustules infected by $S$. filum. Fifty percent of all $P$. graminis subsp. graminicola pustules were infected when $S$. filum was inoculated onto erumpent pustules and incubated above $5^{\circ} \mathrm{C}$ for $48 \mathrm{~h}$ while exposed to

mist. Plants inoculated with both fungi under controlled conditions and then planted into the field had a significantly greater proportion of $P$. graminis subsp. graminicola pustules infected with $S$. filum, and a significantly reduced $P$. graminis subsp. graminicola overwintering population, compared with plants inoculated with $P$. graminis subsp. graminicola only. First-year stands of perennial ryegrass treated in the field with monthly applications of $S$. filum had more than 10 times the proportion of pustules infected with $S$. filum and $50 \%$ less $P$. graminis subsp. graminicola disease compared with the nontreated controls. In comparison, plants with one application of fungicide during the winter had $98 \%$ lower $P$. graminis subsp. graminicola severity than the $P$. graminis subsp. graminicola-only control There were no effects of $S$. filum or fungicide application on rust severity in 2- or 3-year-old perennial ryegrass stands.
\end{abstract}

Perennial ryegrass (Lolium perenne L.) is a cool-season seed crop intensively cultivated in the Pacific Northwest of the United States, New Zealand, and parts of Europe $(3,37,38)$. The most damaging disease of perennial ryegrass in the Pacific Northwest is stem rust, caused by the fungus Puccinia graminis subsp. graminicola Z. Urb. If untreated with fungicide, stem rust can cause reductions in seed yields exceeding $90 \%$ (24).

Weather conditions and host growth during the cropping season (spring and summer) play a major role in determining the severity of the stem rust epidemic. These factors have been combined into a mathematical model that predicts disease severity based on daily weather inputs, host stage, and initial spring rust severity $(25,26,28)$. The model predicts that disease severity during the course of the epidemic is proportional to the initial amount of rust in the spring, if all other variables are held constant. Other studies have found that autumn planting date, cultivar, and stand age all affect spring and summer epidemic severity of other rust diseases in the Pacific Northwest $(6,19,33)$. Late-autumn plantings of perennial ryegrass have significantly less stem rust severity during the epidemic than those planted earlier in the fall, probably due to

Corresponding author: W. F. Pfender, E-mail: pfenderw@onid.orst.edu

The use of trade, firm, or corporation names in this publication is for the information and convenience of the reader. Such use does not constitute an official endorsement or approval by the United States Department of Agriculture or the Agricultural Research Service of any product or service to the exclusion of others that may be suitable.

Accepted for publication 23 March 2012.

http://dx.doi.org/10.1094/PDIS-10-11-0837-RE

This article is in the public domain and not copyrightable. It may be freely reprinted with customary crediting of the source. The American Phytopathological Society, 2012. lower overwintering population of the pathogen (27). However, late planting results in a yield reduction, as demonstrated by a $23 \%$ lower seed yield compared with earlier planted stands when stem rust is kept equally low in both stand types through the use of fungicides (20). Reducing the overwintering P. graminis subsp. graminicola population with a biological control organism could reduce the severity of the spring epidemic without incurring the yield penalty of late planting.

Considerable research has been conducted in evaluating biological control strategies for reducing severity of foliar diseases $(8,11,36)$. Some bacteria (Pantoea agglomerans and Erwinia uredovora; 10) and fungi (Cladosporium tenuissimum; 1) exude extracellualar lytic enzymes that inhibit the germination of urediniospores. Other fungi, including Simplicillium lanosoniveum, Verticillium lecanii, and Aphanocladium album, can colonize the rust sorus and decrease the number of urediniospores produced $(11,14,36)$. Of the organisms studied, the mycoparasite Sphaerellopsis filum (Biv.) B. Sutton (teleomorph Eudarluca caricis (Biv.) O.E. Erikss.) has shown the greatest potential in controlling a wide range of rust diseases, in that it colonizes 369 rust species $(13,15,21,23)$.

E. caricis (synonyms Sphaeria filum, Darluca filum, and E. filum) is an ascomycete in the order Pleosporales and family Phaeosphaeriaceae. The teleomorph is rarely found but has been well described living in the sori of the blackberry rust fungus (Phragmidium violaceum). It consists of black-brown stromata with pseudothecia 120 to $260 \mu \mathrm{m}$ in size (39). Pycnidia of the anamorph, Sphaerellopsis filum, are black, 90 to $200 \mu \mathrm{m}$ in diameter, and have distinct ostioles which excrete hyaline conidiospores [13 to 18 by 3 to $5 \mu \mathrm{m}$ ] in cirrhi (30). Spatial clustering of genotypes in the field, as well as a morphology characterized by gelatinous appendages on the ends of the conidia, indicate that conidia are splash dispersed (2). It is not certain whether the fungus regularly undergoes sexual recombination or what triggers it to enter the teleomorphic stage but there is considerable genetic variation in field populations $(2,22)$. 
$S$. filum grows and sporulates on artificial media containing malt extract or potato dextrose agar (PDA) $(4,7,16,22,31,34)$. In controlled experiments, $S$. filum can infect $93 \%$ of Cronartium fusiforme and $76 \%$ of Puccinia triticina (syn. P. recondita) uredinia when conidia are applied to rust-infected plants and incubated under moist conditions $(16,35)$. When infected with $S$. filum, Melampsora epitea urediniospore production is reduced by 64 to $98 \%$ (40). A simulation model which integrates wheat leaf area and $P$. triticina-S. filum biological interactions estimated that leaf rust severity would be reduced by 60 to $80 \%$ if S. filum infected 40 to $60 \%$ of the pustule surface (12).

Under scanning electron microscope analysis, S. filum hyphae are seen penetrating urediniospores and are interwoven throughout uredinia of leaf rust ( $P$. triticina) and stem rust $(P$. graminis $\mathrm{f}$. $\mathrm{sp}$. tritici) $(5,30)$. Shortened lifespan and reduced spore production of S. filum-infected uredinia are thought to be the underlying mechanisms responsible for observed suppression of oak rust (caused by C. fusiforme) and willow rust (caused by M. epitea) epidemics in the field $(16,40)$.

Field studies of $S$. filum infecting rust uredinia have been limited in scope. In addition, infection parameters, including host age and the moisture and temperature conditions required for infection, have not been clearly established $(16,35)$. The purpose of this study is to determine whether $S$. filum can infect $P$. graminis subsp. graminicola uredinia on perennial ryegrass during the winter and subsequently reduce the ryegrass stem rust severity of the spring epidemic. The experiments seek to quantify (i) the ideal infection conditions for $S$. filum on $P$. graminis subsp. graminicola uredinia on perennial ryegrass plants, (ii) the effects of $S$. filum on P. graminis subsp. graminicola urediniospore production and viability, and (iii) the effects of $S$. filum parasitism on the P. graminis subsp. graminicola population size in the field over the winter and into the spring epidemic.

\section{Materials and Methods}

Glasshouse plants. Seed of perennial ryegrass 'Jet', highly susceptible to stem rust, were planted in a soilless potting mix (Sunshine Growing Mix; Sun Gro Horticulture Inc., Bellevue, WA) in pots ("Cone-tainer", 3.8 by $21 \mathrm{~cm}$; Stuewe \& Sons Inc., Corvallis, OR), one seed per pot. Seed were kept constantly moist until three leaves emerged, at which point the pots were irrigated by placing them in water for 2 days every week, and fertilized every 2 weeks with aliquots from a solution of $6 \mathrm{mg}$ of $\mathrm{N}, 5.4 \mathrm{mg}$ of $\mathrm{P}_{2} \mathrm{O}_{5}$, and 6 $\mathrm{mg}$ of $\mathrm{K}_{2} \mathrm{O}$ in 4 liters of water. Plants were grown in a glasshouse maintained at day and night temperatures of 20 and $15^{\circ} \mathrm{C}$, respectively, with a 12-h day length, and they were periodically trimmed to a height of $8 \mathrm{~cm}$ until time of inoculation, 2 to 5 months after planting.

Controlled inoculation with $\boldsymbol{P}$. graminis subsp. graminicola. Urediniospores were obtained each year from multiple-cultivar perennial ryegrass field plantings at the Oregon State University Hyslop Experimental Farm $\left(44^{\circ} 38^{\prime} \mathrm{N}, 123^{\circ} 12^{\prime} \mathrm{W}\right)$. Spores were dried at $30 \%$ relative humidity overnight, stored at $-60^{\circ} \mathrm{C}$, and heat shocked at $43^{\circ} \mathrm{C}$ for $1.5 \mathrm{~min}$ before use (28). A spore suspension (approximately $2 \times 10^{5}$ spores $/ \mathrm{ml}$ ) was made for each inoculation by adding spores at $1 \mathrm{mg} / \mathrm{ml}$ of light mineral oil (Isopar $\mathrm{M}$; ExxonMobile Chemical Co., Houston). To document spore viability, a $50-\mu \mathrm{l}$ sample of the spore suspension was placed on water agar and incubated in the dark at $23 \pm 2^{\circ} \mathrm{C}$, and spore germination was determined after $24 \mathrm{~h}$ by counting the number of spores out of 100 that had a germ tube longer than the spore width. Each $500-\mu l$ aliquot of spore suspension was mixed immediately before being sprayed onto seven plants with a handheld Venturi atomizer operating at $21 \mathrm{kPa}$. After the oil dried (approximately $30 \mathrm{~min}$ ), inoculated plants were placed in a mist chamber at $20 \pm 4^{\circ} \mathrm{C}$ with a $15-\mathrm{h}$ dark period immediately followed by a 4 -h light period. Mist was run for $15 \mathrm{~min}$ at 2-h intervals during the dark period and continuously during the light period, to keep the leaves consistently moist.

Controlled inoculation with S. filum. S. filum conidia were originally harvested from parasitized rust pustules infecting peren- nial ryegrass leaves in the field in 2003. Three monoconidial isolates (SF1, SF2, and SF3) were obtained from inoculated rust pustules in the glasshouse, maintained separately on PDA, and used as a mixture for the experiments. Conidia were stored at $-60^{\circ} \mathrm{C}$ in a $15 \%$ glycerol solution. Conidial suspensions were transferred to PDA amended with $300 \mathrm{mg}$ of Bacto Tryptone and $150 \mathrm{mg}$ of Bacto Yeast Extract, and incubated for 2 days under UV light (40W blacklight; GE, Fairfield, CT) at $23^{\circ} \mathrm{C}$ and then under gro-lights (40-W, Gro-Lux; Sylvania, Danvers, MA) at $23^{\circ} \mathrm{C}$ for 2 to 3 weeks (20). Mucilaginous cirrhi of conidia were harvested from pycnidia by means of a sterile blade and placed into centrifuge tubes with 1 $\mathrm{ml}$ of sterilized water containing $0.05 \mathrm{M} \mathrm{MgSO}_{4}$ to help prolong viability of the conidia (unpublished data). After mixing for $30 \mathrm{~s}$, the suspension was transferred to a larger container and adjusted to $10^{5}$ conidia/ml with $0.05 \mathrm{M} \mathrm{MgSO}_{4}$. The resulting suspension was sprayed on each rust-infected plant $(1.5 \mathrm{ml} /$ plant $)$ with an aerosol sprayer (Preval; Precision Valve Corporation, Yonkers, NY).

Effects of mist duration. Plants were inoculated with $P$. graminis subsp. graminicola 10,5 , or 0 days prior to the day on which all plants were inoculated with $S$. filum. These intervals constituted durations of 1.2, 0.6, and $0.0 P$. graminis subsp. graminicola latent periods (25) as calculated by temperature measurements taken in the glasshouse. Immediately after the plants dried from the $S$. filum inoculation, they were placed on a bench in a glasshouse under a misting system that kept the leaves wet (misting leaves for $30 \mathrm{~min}$ every $2 \mathrm{~h}$ ) with day and night temperatures of 15 and $20^{\circ} \mathrm{C}$, respectively. At $0,2,4,6,12,24,48,72$, and $120 \mathrm{~h}$ after $S$. filum inoculation, 12 plants (4 replicate plants from each rust-inoculated age group) were transferred to a glasshouse bench where plants were not misted, thus preventing subsequent $P$. graminis subsp. graminicola infections from occurring. Additional control treatments, inoculated with $P$. graminis subsp. graminicola but not $S$. filum, were given 0 or $120 \mathrm{~h}$ of mist treatment. Trials were scored for $P$. graminis subsp. graminicola and $S$. filum severity approximately $1.6 \pm$ $0.2 P$. graminis subsp. graminicola latent periods after $S$. filum inoculation. The experiment was repeated once.

Effects of temperature. Plants were inoculated with $P$. graminis subsp. graminicola and $S$. filum as described in the mist experiment above. Immediately after the plant leaves dried following $S$. filum inoculation, the plants were placed in a growth chamber that misted plants for 2 min every $2 \mathrm{~h}$, keeping the leaves wet for $48 \mathrm{~h}$. Treatment temperatures were $5,10,15,20$, and $25^{\circ} \mathrm{C}$. Because of limited growth chamber availability, only one of the listed treatments was conducted at a time, paired each time with a treatment at $15^{\circ} \mathrm{C}$ to allow normalization of results across trials. The choice of chamber to use for the $15^{\circ} \mathrm{C}$ was done by random-number selection independently for each trial. Each treatment consisted of 30 plants (5 inoculated with $S$. filum and 5 noninoculated plants from each $P$. graminis subsp. graminicola-inoculated age group). After the 48-h mist exposure, plants were kept without misting in the growth chambers at the specified treatment temperature to prevent subsequent infections. The experiment was scored as described in the mist-duration experiment and was repeated.

Effects of $S$. filum on $P$. graminis subsp. graminicola spore production and germination. To reduce variability in rust spore production that might arise from host genetic differences, plants raised in a glasshouse were vegetatively propagated so that 12 copies of each of 4 clones were obtained. All plants were inoculated with $P$. graminis subsp. graminicola and left on a glasshouse bench for 6 days ( 0.7 stem rust latent periods) while the infections incubated. Four replications of each of the four clones (16 plants) were then assigned to each of three treatments: (i) inoculated with $S$. filum conidia suspended in $0.05 \mathrm{M} \mathrm{MgSO}_{4}$, (ii) sprayed with the $\mathrm{MgSO}_{4}$ solution as a check, or (iii) left untreated. Immediately after the plants had dried, they were placed under a misting system for $48 \mathrm{~h}$, as described in the mist-duration experiment, then transferred to a glasshouse bench without mist. Starting when pustules erupted, spores from four pustules per plant were collected every 2 to 3 days into gelatin capsules fitted on a small vacuum spore sampler (32). Pustules from four plants (16 pustules) made up one 
measurement replication. Isopar $\mathrm{M}$ oil $(100 \mu \mathrm{l})$ was added to each capsule and thoroughly mixed with the spores, and $20 \mu \mathrm{l}$ of the resulting suspension was placed on a hemacytometer (Fisher Scientific, Pittsburg). The spores were counted and the total number of spores produced per pustule per day was calculated. An additional aliquot $(20 \mu \mathrm{l})$ of the spore suspension was spread on a water agar plate, and the spore germination percentage was determined by microscopic observation after $24 \mathrm{~h}$ of incubation at $22^{\circ} \mathrm{C}$ in the dark. Two trials of the experiment were completed.

Field experiments. The effects of $S$. filum on $P$. graminis subsp. graminicola populations in the field over the winter were investigated at two sites with two types of experiments during the 200910 and 2010-11 field seasons. Site 1 was at the Oregon State University Hyslop Experiment Farm near Corvallis, OR $\left(44^{\circ} 38^{\prime} \mathrm{N}\right.$, $123^{\circ} 12^{\prime} \mathrm{W}$ ). Site 2 was a commercial perennial ryegrass field near Junction City, OR ( $\left.44^{\circ} 23^{\prime} \mathrm{N}, 123^{\circ} 20^{\prime} \mathrm{W}\right)$. In experiment 1 ("controlled inoculation experiment") plants were inoculated with $P$. graminis subsp. graminicola and $S$. filum under controlled conditions, and then out-planted to the field. In experiment 2 ("field inoculation experiment") field plants were naturally infected with P. graminis subsp. graminicola, and S. filum conidia were applied in the field using a backpack sprayer. Weather conditions were collected at both sites with a data logger (CR10X; Campbell Scientific, Logan, UT) that had sensors for temperature and leaf wetness at the canopy level, rainfall, and relative humidity.

Field observations of naturally occurring infections. In 200003 , first- and second-year plantings of perennial ryegrass were observed for the proportion of $P$. graminis subsp. graminicola uredinia infected with $S$. filum over the winter (December to March). Plants (six replications of $10 \mathrm{~cm}$ of row) from both firstand second-year perennial ryegrass plantings were randomly cut from field plantings. The leaves within each cut sample were mixed and observed under a dissecting microscope until $100 P$. graminis subsp. graminicola pustules were counted. The numbers of $P$. graminis subsp. graminicola uredinia and uredinia containing $S$. filum pycnidia were tabulated and used to determine the proportion of uredinia infected with S. filum.

Field experiment 1: controlled inoculations transplanted to the field. Seed of perennial ryegrass Jet, 'Morningstar', and 'Linn' were planted in rows in an outdoor planting bed on 7 October 2009 and 15 September 2010. In the field experiments, the perennial ryegrass "plant" unit consisted of $10 \mathrm{~cm}$ of row (6 to 10 individual plants). The $10-\mathrm{cm}$ plant units were dug from the rows and placed in pots (one unit per pot) on 11 December and 6 November for the 2009 and 2010 experiments, respectively. The potted plants were brought into a glasshouse and inoculated with $P$. graminis subsp. graminicola and $S$. filum as described in the spore production experiment; however, in this experiment, only $P$. graminis subsp. graminicola infections that were 7 days $(0.8$ stem rust latent periods) old were inoculated with $S$. filum. The three treatments were (i) noninoculated plants, (ii) $P$. graminis subsp. graminicola-inoculated plants, and (iii) P. graminis subsp. graminicola-inoculated plants inoculated with $S$. filum. After $S$. filum inoculation, all treatments were placed under the mist system for $48 \mathrm{~h}$, then out-planted to field sites 1 and 2 as described below. Plants were scored weekly for $S$. filum and $P$. graminis subsp. graminicola severity while in the field.

At site 1, each experimental unit consisted of two identically treated plants (i.e., two $10-\mathrm{cm}$ units) spaced $0.6 \mathrm{~m}$ (two rows) apart from one another. At site 1 in 2009, treatments were applied to plants of Jet and experimental units were set out $11 \mathrm{~m}$ apart from one another, randomized in a 2-by-45-m plot area in a field of Jet. In 2010, treatments were applied to Jet, Morningstar, and Linn, and experimental units were set out $1.2 \mathrm{~m}$ apart from one another into a plot of 'Manhattan 5' (moderately resistant to P. graminis subsp. graminicola infection). In each year, there were four replications per treatment in a completely randomized design.

At site 2, each experimental unit within a treatment consisted of a plant (10 cm of row). At site 2, experimental units were set out 2 $\mathrm{m}$ apart, randomized within a $35-$ by-35-m plot in a commercial field of 'Silver Dollar'. In 2009-10 at site 2, treatments were applied to plants of Jet and Morningstar. In 2010-11, treatments were applied to plants of Jet, Morningstar, and Linn. In each year, there were six replications in a completely randomized design. Plants were scored as previously described in the field during both years.

Field experiment 2: field inoculations. Field inoculation experiments were conducted at site 1 only. During the 2009-10 season, four blocks ( 2 by $45 \mathrm{~m}$ ) of perennial ryegrass Jet were planted on 7 October 2009 and were designated as the first-year stand. Second-year stand plots of Jet had been planted on 29 September 2008. For the 2010 season, Jet and Linn were planted on 15 September and designated as first-year stand plots. Third-year stand plots of Jet and Linn had been planted on 29 September 2008. The first-year and established (second- or third-year) stand blocks were randomly placed in a larger field with a minimum distance of $4.5 \mathrm{~m}$ maintained between blocks to allow access for spraying and disease assessment without disturbing adjacent blocks. Planting and maintenance procedures following standard agronomic practices have been described previously (27).

Each block was divided into four treatment plots, each measuring 2 by $11 \mathrm{~m}$ and arranged in a randomized complete block design. The four treatments were (i) a nontreated control, (ii) one application of $S$. filum in the winter, (iii) monthly applications of $S$. filum from late fall until late spring, or (iv) one application of the fungicide Quilt (7\% azoxystrobin and $11 \%$ propiconazole; Syngenta Inc., Basel, Switzerland) in the winter. A 3-by-2.1-m buffer (sprayed with Quilt to minimize the spread of disease) was maintained between treatment plots in 2010-11.

S. filum was applied by first harvesting conidia from approximately 80 PDA plates into 12 liters of sterilized $0.05 \mathrm{M} \mathrm{MgSO}_{4}$ in water to give a final concentration of $10^{5} \mathrm{spores} / \mathrm{ml}$. The conidial suspension was applied to plots at a rate of $10^{9}$ spores/ha (12 liters per ha) by means of a $\mathrm{CO}_{2}$-pressurized backpack sprayer operated at a pressure of $138 \mathrm{kPa}$ (20 psi). The suspension was applied also to two PDA plates to test for contamination and to quantify the germination of the $S$. filum conidia.

One-time applications of $S$. filum were applied on 15 November 2009 or 30 November 2010 . Monthly applications of $S$. filum were applied on 15 November, 15 December, 24 January, 21 March, 14 April, 3 May, and 26 May during the 2009-10 winter and on 24 October, 30 November, 27 December, 14 February, 7 March, and 6 April during the 2010-11 winter. Quilt was applied at a rate of $1,500 \mathrm{ml}$ in 75 liters of water per hectare $(0.3 \mathrm{~kg}$ a.i./ha) at a pressure of $207 \mathrm{kPa}$ (30 psi) on 28 January in the 2010 experiment and 4 February in the 2011 experiment.

Treatment plots were observed for $P$. graminis subsp. graminicola and $S$. filum severity by counting the number of $P$. graminis subsp. graminicola pustules and the number of pustules infected with S. filum. Specifically designated plants in two replications per treatment were observed repeatedly during the experiment. These plants were marked by arbitrarily selecting $10 \mathrm{~cm}$ of row and repeatedly scoring two to four times a month, taking care not to disturb the plants.

Effects of fungicide on $\boldsymbol{S}$. filum germination. The effects of three fungicides widely used to prevent $P$. graminis subsp. graminicola epidemic development were tested for their effect on the viability of $S$. filum spores. The fungicides used were Bravo (54\% chlorothalonil; Syngenta Inc.), Quadris (22.9\% azoxystrobin; Syngenta Inc.), and Tilt (41.8\% propiconazole; Syngenta Inc.). For each fungicide, filter discs (5.5-mm-diameter Whatman 42 ashless filter paper; Kent, UK) were saturated with a dilution series of the formulated products $(1,1: 10,1: 100,1: 500,1: 1000$, and a water control). The fungicide-soaked discs were placed on water agar plates (three replications of each dilution) that had been sprayed with a conidial suspension of $S$. filum in $0.05 \mathrm{M} \mathrm{MgSO}_{4}$ (as described in the controlled inoculation experiments above). The plates were closed and incubated for 2 days under UV light at $23^{\circ} \mathrm{C}$ and 3 days under gro-lights at $23^{\circ} \mathrm{C}$, with $12 \mathrm{~h}$ of dark and light periods. The plates were scored for the zone of inhibition, where germination (germ tube longer than the spore width) oc- 
curred in less than $10 \%$ of the spores. The distance between the edge of the fungicide filter disc and the delineated inhibition edge was measured with a ruler.

Data analysis. The mist-duration and temperature experiment counts of $P$. graminis subsp. graminicola pustules or pustules infected with $S$. filum were expressed as total number of $P$. graminis subsp. graminicola pustules or the proportion of $P$. graminis subsp. graminicola pustules infected with $S$. filum. A multiple linear regression analysis on log-transformed data was performed to determine the relationship between mist duration and pustule age on the proportion of $P$. graminis subsp. graminicola pustules infected with S. filum. The 0- and 120-h mist-duration observations were removed from the analysis to prevent skewness, because the effects of mist leveled off at $72 \mathrm{~h}$ and there were no $P$. graminis subsp. graminicola infected with $S$. filum in the 0-h treatment. In addition, the 0 -day-old rust treatment, which was rarely infected by the mycoparasite and, therefore, had virtually invariant data, was omitted from analysis in the mist-duration experiment.

There were sufficient growth chambers available to conduct only two temperature treatments in each test; therefore, chambers were randomly reassigned to a different temperature for each trial and a $15^{\circ} \mathrm{C}$ treatment was included in each trial as a standard (25). Because inoculum conditions can vary among trials, we standardized observations by expressing the level of $S$. filum infection in each trial as a proportion of that produced in the standard $15^{\circ} \mathrm{C}$ treatment. Statistical analysis (analysis of variance [ANOVA]) of proportion pustules infected in the $15^{\circ} \mathrm{C}$ treatment in the different growth chambers among the multiple trials showed no effect of growth chamber and no interaction of chamber with plant age treatment $(P=0.13$ and 0.14 , respectively); therefore, any nontemperature effect of growth chamber was implicitly included as random experimental error. Temperature, $P$. graminis subsp. graminicola pustule age at time of $S$. filum inoculation, and trial were factors in the three-way ANOVA for the temperature experiment.

Weibull (four-parameter) curves were fit to the data for spore production and for spore production multiplied by spore viability

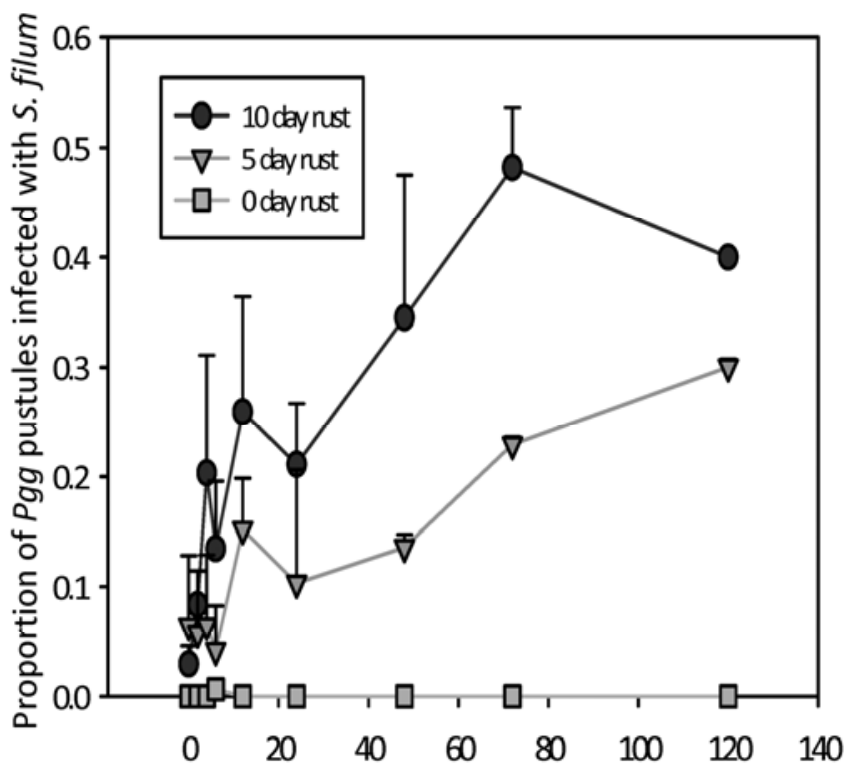

Mist duration (h)

Fig. 1. Effects of pustule age and leaf wetness on the proportion of Puccinia graminis subsp. graminicola $(P g g)$ pustules infected with Sphaerellopsis filum. Perennial ryegrass plants were inoculated with $P$. graminis subsp. graminicola 10 , 5 , or 0 days before they were treated with a conidial suspension of $S$. filum. Plants were then incubated at day and night temperatures of 15 and $20^{\circ} \mathrm{C}$, respectively. Treatments (four replications) were misted for 30 min every $2 \mathrm{~h}$ to maintain wet leaves for the durations shown, and scored after 1.5 P. graminis subsp. graminicola latent periods. Each data point is the mean and standard error of the mean between two experiments. for each treatment, using SigmaPlot (SigmaPlot v. 11.0; Systat Software, San Jose, CA). Spore production and viability data were analyzed by three-way and four-way ANOVA, respectively. The factors in the analysis were treatment, host genotype, trial, and, for the germination experiment, days after inoculation.

Counts of rust pustules per $10 \mathrm{~cm}$ of row in the field experiment were plotted against time, and the area under the disease progress curve (AUDPC) was calculated from this graph (18) for the period between 1 March and the end of the observations (11 June, 2010 and 2 June 2011) by summing areas under the trapezoids produced from the data points joined by straight lines. This calculation of AUDPC was done to determine any treatment differences in rust severity that were manifested during the first part of the crop production season. The AUDPC values for proportion of $P$. graminis subsp. graminicola pustules with $S$. filum were obtained from data across the entire sample period (14 November to 11 June 2009-10 and 11 October to 2 June 2009-10). Field data were analyzed using three-way ANOVA. The factors were stand age, treatment, and block. Multiple comparisons were made using Tukey's HSD (honestly significant difference) method. Analysis was conducted using R (R Development Core Team [2011], R Foundation for Statistical Computing, Vienna).

\section{Results}

Effects of mist duration. Multiple linear regression analysis of log-transformed data showed that mist duration between 2 and $72 \mathrm{~h}$ and $P$. graminis subsp. graminicola pustule age at the time of $S$. filum inoculation had significant $(P<0.006$ and $P=0.02$, respectively) effects on the proportion of $P$. graminis subsp. graminicola pustules infected with $S$. filum (Fig. 1). Mist duration between 2 and $72 \mathrm{~h}$ was positively correlated $(P<0.006)$ with the proportion of pustules infected with S. filum. Pustules that were 10 days old had a higher $(P=0.02)$ percentage of pustules infected with $S$. filum across all mist durations than the pustules that were 5 days old at the time of $S$. filum inoculation. There was not a significant interaction $(P=0.06)$ between mist duration and pustule age.

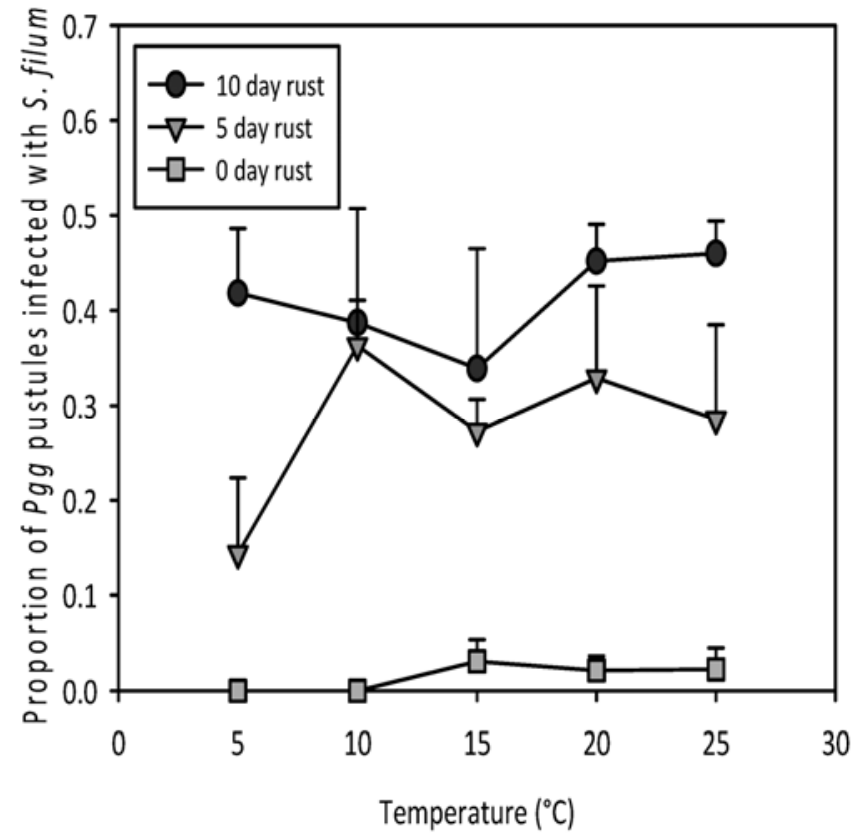

Fig. 2. Effect of temperature and pustule age on the proportion of Puccinia graminis subsp. graminicola $(P g g)$ pustules infected with Sphaerellopsis filum. Perennial ryegrass plants were inoculated with a conidial suspension of $S$. filum 10,5 , or 0 days after they were inoculated with $P$. graminis subsp. graminicola. Plants were placed in growth chambers at the constant temperatures shown with $48 \mathrm{~h}$ of mist. After 1.5 P. graminis subsp. graminicola latent periods, plants were scored for $P$. graminis subsp. graminicola and $S$. filum severity. Data points represent the mean (five replications) and standard error of the mean in one trial of the experiment. A second trial produced similar results and the same conclusions. 
Effects of temperature. The mean overall effect of the temperature $\left(5\right.$ to $\left.25^{\circ} \mathrm{C}\right)$ at which $S$. filum was incubated was significant $(P$ $=0.03)$ on the proportion of $P$. graminis subsp. graminicola pustules infected with $S$. filum (Fig. 2), although it was only among the 5 -day-old pustules that infection was lower at $5^{\circ} \mathrm{C}$ than at the other temperatures. $P$. graminis subsp. graminicola pustule age at the time of $S$. filum inoculation had a significant effect $(P<0.001)$ across all temperatures on the proportion of $P$. graminis subsp. graminicola pustules infected with $S$. filum (Fig. 2). The overall effect of pustule age averaged across the temperatures tested was that $S$. filum infected $13 \%$ more 10-day-old $P$. graminis subsp. graminicola pustules than 5-day-old pustules $(P<0.001)$, and 36\% more 10 -day-old pustules than 0 -day-old pustules $(P<0.001)$. There was no significant interaction between temperature and age $(P=0.43)$, trial and temperature $(P=0.73)$, or trial and age $(P=$ $0.74)$.

Rust spore production and germination. Nontreated $P$. graminis subsp. graminicola pustules produced 39,000 spores over their lifetime, more than double $(P<0.001)$ the 18,000 produced when infected with S. filum (Fig. 3A). There was no effect of host genotype on the number of spores produced $(P=0.064)$ and no interaction between host genotype and treatment $(P=0.99)$.

$S$. filum reduced the overall average viability of spores by $4.75 \%$ $(P<0.001)$. Spore viability multiplied by daily spore production was plotted against days since $P$. graminis subsp. graminicola inoculation (Fig. 3B). Weibull (four-parameter) curves were fit to each treatment and plotted with the averages of each trial. The standard form for the Weibull curve is $f(x)=a \times((c-1) / c)^{\wedge}((1-$ $c) / c) \times\left(\operatorname{abs}\left((x-x 0) / b+((c-1) / c)^{\wedge}(1 / c)\right)^{\wedge}(c-1)\right) \times \exp (-\operatorname{abs}((x-$ $\left.\left.\left.x 0) / b+((c-1) / c)^{\wedge}(1 / c)\right)^{\wedge} c+(c-1) / c\right)\right)$, for $(x \leq x 0-b \times((c-$ $1) / c)^{\wedge}(1 / c)$. The parameter estimates for the $P$. graminis subsp. graminicola spore curve as a function of days after infection are $a$ $=5,500, b=5.44, c=1.01$, and $x 0=14.30$. The parameter estimates for the $P$. graminis subsp. graminicola-only treatment for the spore curve multiplied by spore viability are $a=5,000, b=5.44, c$ $=1.11$, and $x 0=14.30$. The parameter estimates for the $S$. filum treatment for the rust spore curve multiplied by spore viability are $a=3,200, b=4.2, c=1.01$, and $x 0=12.12$. The coefficient and standard error of the first parameter of each curve (which set the maximum) for each treatment are (i) nontreated P. graminis subsp. graminicola, 5,500 \pm 204 ; (ii) $P$. graminis subsp. graminicola with $0.05 \mathrm{M} \mathrm{MgSO}_{4}, 5,540 \pm 263$; and (iii) P. graminis subsp. graminicola with $S$. filum, 3,200 \pm 370 (the adjusted $r^{2}$ values are 0.74 , 0.63 , and 0.83 , respectively).

Field observations. In 2000-03, first- and second-year plantings of perennial ryegrass were observed for the proportion of $P$. graminis subsp. graminicola uredinia infected with $S$. filum over the winter (December to March). In all, 2\% of the pustules were infected on the first-year plantings, whereas the second-year plantings had $25 \%$ of the pustules infected with S. filum (significantly different, $P<0.05$ ). There was also a significant difference between the pustules infected with S. filum on living leaves and dead leaves. On the first-year plantings, there were $4 \%$ more pustules infected on the dead leaves than on live leaves (not significantly different at $P>0.05$ ). On the second-year plantings, there were $43 \%$ more pustules infected with $S$. filum on the dead leaves than on the live leaves (different at $P<0.05$ ).

Field experiment 1: controlled inoculations. Results of the controlled inoculations with $S$. filum on $P$. graminis subsp. graminicola-infected perennial ryegrass plants transplanted to the field are shown in Figure 4 (site 1) and Figure 5 (site 2). The area under the disease progress curve was calculated from 1 March through June for $P$. graminis subsp. graminicola pustule data, and across all observation dates in a given year for the proportion of $P$. graminis subsp. graminicola pustules infected with $S$. filum. Means and the statistical conclusions from one- and two-way ANOVA are summarized for sites 1 and 2 (Table 1). Analysis is shown for data within a site but not between sites because of a significant interaction effect between sites. There were significant effects of $S$. filum infection on $P$. graminis subsp. graminicola pustule severity and the proportion of $P$. graminis subsp. graminicola pustules infected with $S$. filum at both sites in 2009-10. In 2010-11, the $P$. graminis subsp. graminicola population did not survive the winter at either site in any treatment; therefore, treatment effects on spring-time $P$. graminis subsp. graminicola severity could not be assessed.

In 2009-10 at site 1, the $S$. filum treatment had only a third as much disease (AUDPC, difference significant at $P=0.013$ ) as the $P$. graminis subsp. graminicola treatment without $S$. filum (Fig. 4; Table 1). Similarly, at site 2 in that year, the $S$. filum treatment had only 5 to $10 \%$ as much disease $(P<0.001)$ as the $P$. graminis subsp. graminicola-only treatment on Jet and Morningstar, respectively (Fig. 5; Table 1). In 2009-10, the S. filum treatment had more $P$. graminis subsp. graminicola pustules infected with $S$. $f$ lum $(P<0.001)$ than the $P$. graminis subsp. graminicola treatment without $S$. filum. Jet had significantly more disease $(P<0.001)$ than Morningstar. Cultivar did not have a significant effect on the proportion of $P$. graminis subsp. graminicola pustules infected with S. filum.

Field experiment 2: field inoculations. Four treatments were applied to first-year and older (second- or third-year) plantings of perennial ryegrass exposed to natural inoculum of $P$. graminis subsp. graminicola at site 1 in 2009-10 and 2010-11. Treatments
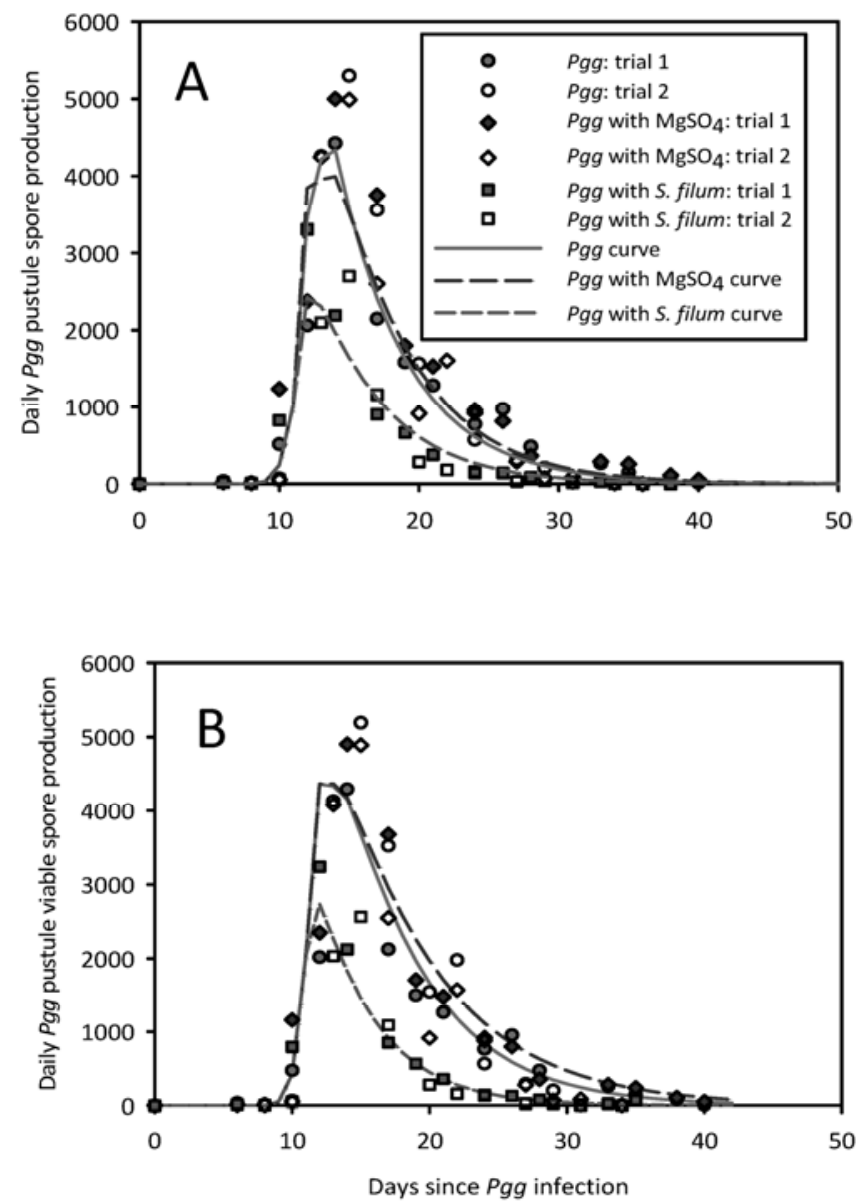

Fig. 3. A, Puccinia graminis subsp. graminicola (Pgg) daily spore production and B, spores produced multiplied by spore viability. Perennial ryegrass 'Jet" plants were inoculated with a $P$. graminis subsp. graminicola spore suspension. After 7 days ( 0.7 rust latent periods), three treatments were applied and plants were subjected to misting for the first $48 \mathrm{~h}$ at day and night temperatures of 20 and $15^{\circ} \mathrm{C}$, respectively. The three treatments applied were (i) a nontreated control, (ii) $0.05 \mathrm{M}$ $\mathrm{MgSO}_{4}$, or (iii) Sphaerellopsis filum conidial suspension in $0.05 \mathrm{M} \mathrm{MgSO}_{4}$. Spores were collected from individual rust pustules every 2 or 3 days and counted with a hemocytometer. Spore viability at each collection time was determined as percent germination on water agar. A Weibull (four-parameter) curve (see text) was fit to the data. Symbols represent means for data from each trial; lines represent Weibull curves calculated for each treatment. 
were (i) nontreated control, (ii) one application of S. filum, (iii) monthly applications of $S$. filum, or (iv) one winter application of Quilt fungicide.

First-year stands of perennial ryegrass treated with one application of $S$. filum did not have significantly less $P$. graminis subsp. graminicola disease than the nontreated control in either year (Fig. 6). First-year stands treated with monthly applications of S. filum had only about $50 \%(P=0.02)$ of the disease severity of the control treatment in 2009-10 (Table 2) but, in 2010-11, the lower disease in this treatment (56\% of the check) was not statistically significant $(P=0.24)$. In both years, first-year stands receiving monthly applications of $S$. filum had a significantly greater proportion $(P<0.03)$ of $P$. graminis subsp. graminicola pustules infected with $S$. filum than the proportion infected in the control treatment.

Quilt fungicide treatments on first-year stands had a P. graminis subsp. graminicola severity that was only $20 \%$ and $1 \%$ that of the control treatment in 2009-10 and 2010-11, respectively (significant at $P<0.001$ in both years) (Table 2). The fungicide treatment did not have a significantly different proportion of $P$. graminis subsp. graminicola pustules infected with $S$. filum than the nontreated control in either year.

Established stands of perennial ryegrass had substantially less $P$. graminis subsp. graminicola disease than the first-year stands in both years (significant at $P<0.001$; Table 2). There were no significant treatment effects ( $S$. filum or fungicide) within these older stands in $2009-10$ or $2010-11$.

Favorable field conditions for $\boldsymbol{S}$. filum infection. Conditions favorable for $S$. filum infection were determined from daily weather measurements (Fig. 7) by finding days between the planting date and 15 April that had a minimum temperature above $5^{\circ} \mathrm{C}$ and six or more hours of leaf wetness. In this period in 2009-10, $24 \%$ of the days were favorable for infection and, in 2010-11, 25\% of these days were favorable for infection.

Effects of fungicide. $S$. filum germination inhibition was measured on water agar against three fungicides along a dilution series (Fig. 8). At concentrations below $0.01 \%$ of the active ingredient (field concentrations are between 0.005 and $0.0005 \%$ ), chlorothalonil and azoxystrobin inhibited $S$. filum germination with a zone of inhibition between 6 and $8 \mathrm{~mm}$. There was no zone of inhibition around these same concentrations of propiconazole. At high concentrations ( $>0.01 \%$ of the active ingredient), all three of the fungicides inhibited $S$. filum germination but inhibition distance was $8 \mathrm{~mm}$ greater for axoxystrobin $(P=0.003)$, and $7 \mathrm{~mm}$ greater for chlorothalonil $(P=0.012)$ than for propiconazole.

\section{Discussion}

Our experiments showed that leaf wetness duration played a significant role in the proportion of $P$. graminis subsp. graminicola
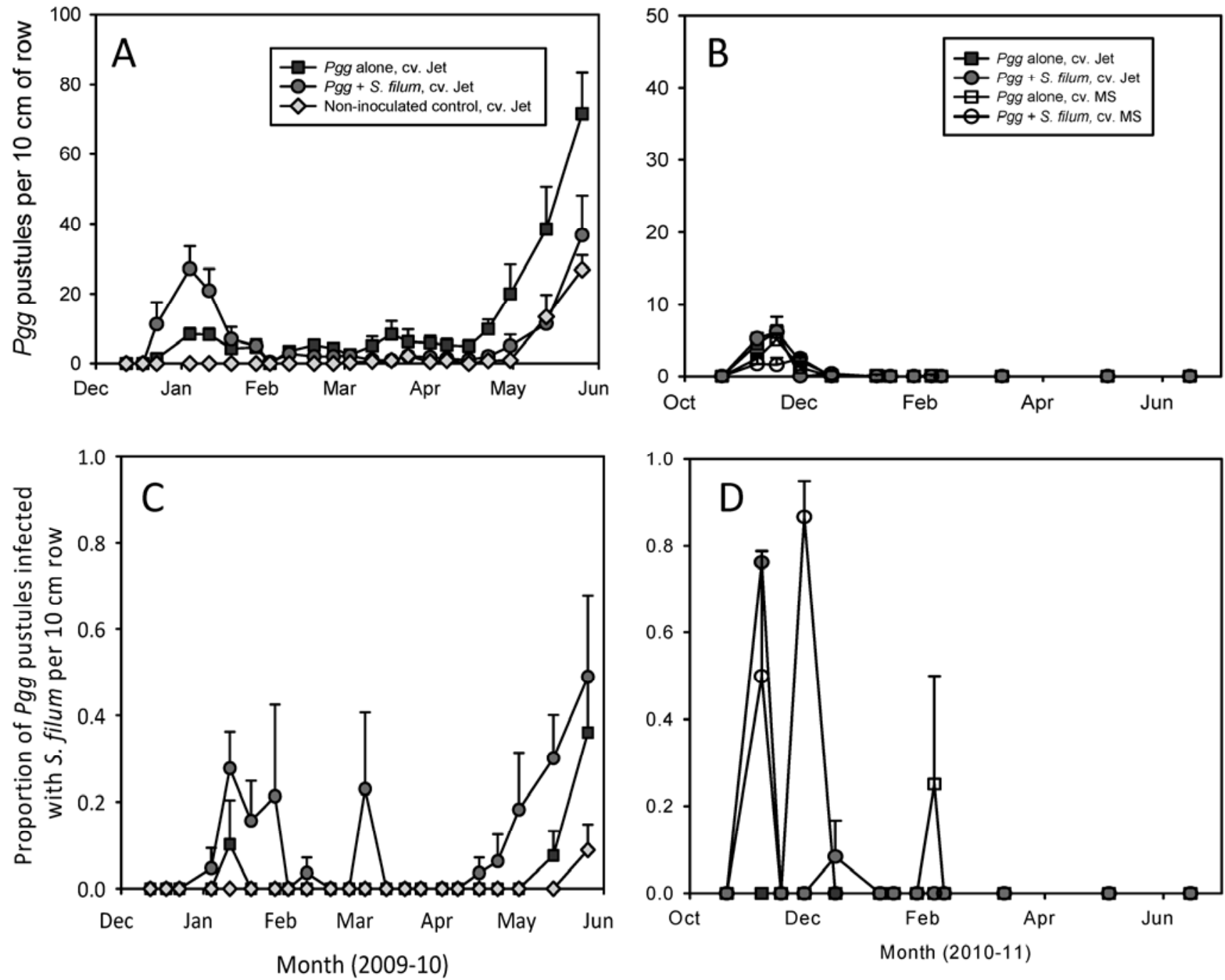

Fig. 4. Site 1 field experiment of Puccinia graminis subsp. graminicola $(P g g)$ and Sphaerellopsis filum applied to ryegrass plants before outplanting. A and B, Number of $P$. graminis subsp. graminicola pustules and $\mathbf{C}$ and $\mathbf{D}$, the proportion of $P$. graminis subsp. graminicola pustules infected with $S$. filum on plants observed repeatedly over the winter. The experiment was conducted in A and C, 2009-10 and B and D, again in 2010-11. Data points are the means and standard error of the mean on six replications of $10 \mathrm{~cm}$ of row. In 2009-10, 'Jet” was used. In 2010-11, Jet, 'Morningstar' (MS), and 'Linn' (not shown; results similar to Jet) were used. Noninoculated plants did not develop P. graminis subsp. graminicola pustules over the winter in 2010-11. 
pustules infected with $S$. filum, as others had shown previously for $S$. filum infection on $C$. fusiforme, $P$. triticina (syn. $P$. recondita), and $M$. larici-epitea. S. filum infected $42 \%$ fewer C. fusiforme pustules with $4 \mathrm{~h}$ of moisture than with $16 \mathrm{~h}$ of moist incubation (16). We found a significant $(P=0.006)$ positive linear relationship, using multiple linear regression, of the proportion of $P$. graminis subsp. graminicola pustules infected with $S$. filum as a function of mist duration, and some infection occurred with as little as $2 \mathrm{~h}$ of mist.

Previous research by others revealed that age of the rust infection can influence success of colonization by S. filum. S. filum does not infect $C$. fusiforme pustules when both fungi are inoculated simultaneously (16) but readily infects $M$. epitea on willow (21) or $P$. triticina on wheat (35) when conidia and urediniospores are inoculated onto leaf tissue simultaneously. Our results were closer to those reported for S. filum on C. fusiforme than for S. filum on $P$. triticina or $M$. epitea. S. filum infected $13 \%$ more 10-day-old $P$. graminis subsp. graminicola pustules than 5-day-old pustules and $36 \%$ more 10 -day-old pustules than 0 -day-old pustules. $P$. graminis subsp. graminicola infections that were 0 days old at the time of $S$. filum inoculation were generally not infected by the mycoparasite.

Incubation temperature had a statistically significant overall effect on the number of $P$. graminis subsp. graminicola pustules infected by $S$. filum but the effect was not marked and all temperatures between 5 and $25^{\circ} \mathrm{C}$ were permissive for infection. Weather data from field site 1 showed that $25 \%$ of the days between the planting date and 15 April in two different years were favorable for $S$. filum infection (temperatures above $5^{\circ} \mathrm{C}$ and $>6 \mathrm{~h}$ of leaf wetness). This research was conducted in Oregon's Willamette Valley, which has a maritime climate where many winter days are sufficiently warm and wet to be conducive for S. filum infection. However, summer conditions are dry and, therefore, less conducive for $S$. filum infection. In our climate, S. filum is most likely to be effective as a biocontrol agent during the overwinter period, when moisture is common and the rust pathogen is relatively disadvantaged by the cooler conditions. S. filum might be applied effectively in other climates in seasons that have relatively warm and moist weather patterns. In continental climates where winter conditions are colder and drier, there may be less opportunity to use $S$. filum as a biocontrol during overwinter survival of the rust fungus.

S. filum colonizes $20.5 \%$ of $M$. larici-epitea pustules on detached willow leaves and reduces spore production by $38.4 \%$ per pustule (23). In our experiments, S. filum infected between 20 and $60 \%$ of $P$. graminis subsp. graminicola pustules and reduced spore production in colonized pustules by $54 \%$. The reduction in $P$. graminis subsp. graminicola spore production is presumed to be the mechanism by which $S$. filum reduces rust epidemics (20). A simulation model that integrated wheat leaf area and $P$. triticina and $S$. filum biology concluded that S. filum would reduce the severity of a leaf rust epidemic by 60 to $80 \%$ when 40 to $60 \%$ of
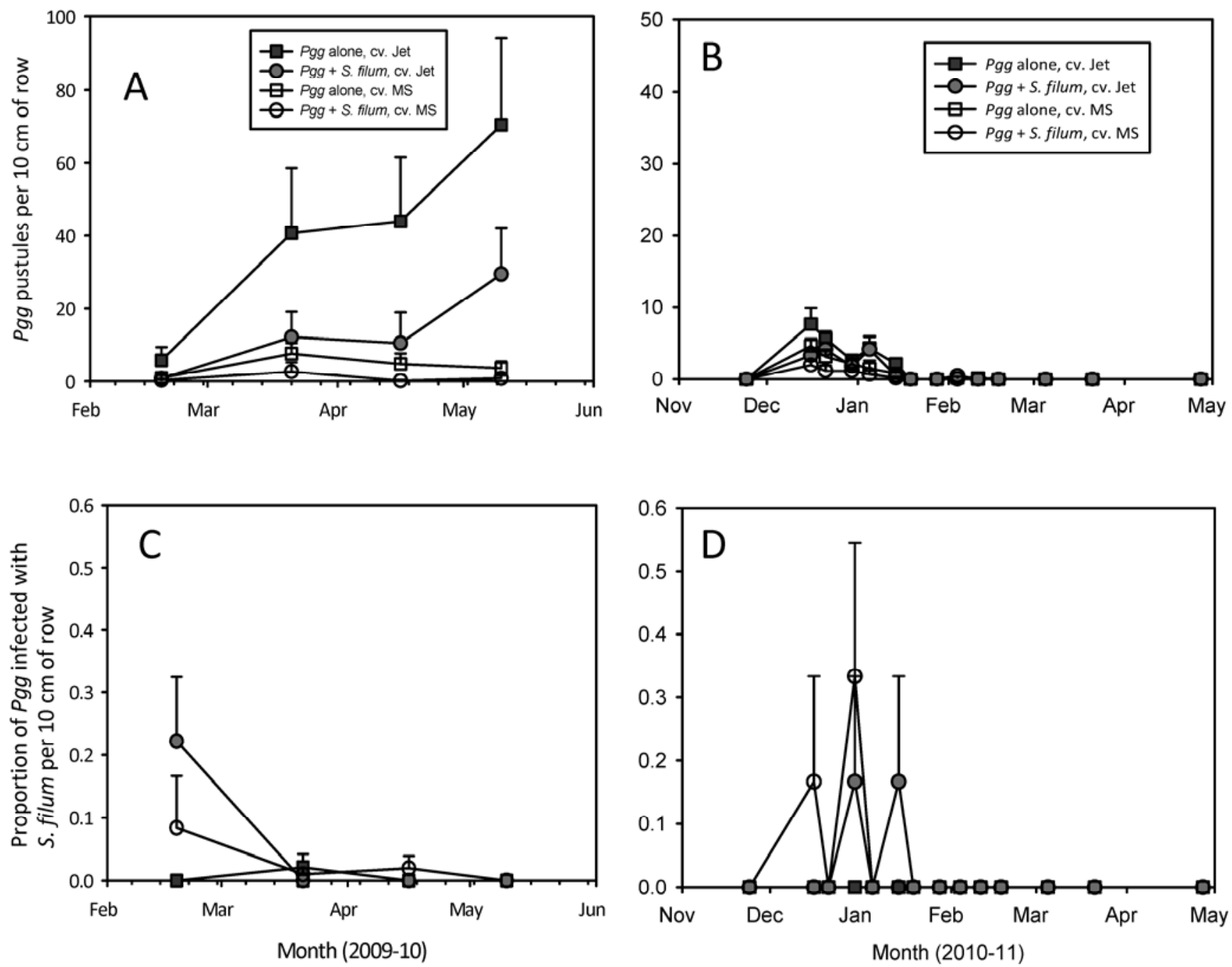

Fig. 5. Site 2 field experiment of Puccinia graminis subsp. graminicola (Pgg) and Sphaerellopsis filum applied to ryegrass plants before outplanting. A and $\mathbf{B}$, Number of $P$. graminis subsp. graminicola pustules and $\mathbf{C}$ and $\mathbf{D}$, the proportion of $P$. graminis subsp. graminicola pustules infected with $S$. filum on plants repeatedly observed over the winter. The experiment was conducted in A and C, 2009-10 and B and D, again in 2010-11. Data points are the means and standard error of the mean on six replications of $10 \mathrm{~cm}$ of row. In 2009-10, 'Jet' and 'Morningstar' (MS) were used. In 2010-11, Jet, MS, and 'Linn' (not shown; results similar to Jet) were used. Noninoculated plants did not develop P. graminis subsp. graminicola pustules over the winter in 2010-11. 
the pustules were colonized (12). An overwintering model that we developed for $P$. graminis subsp. graminicola on perennial ryegrass (9) predicted that $S$. filum would reduce the early spring epidemic by 20 to $70 \%$ when 20 to $60 \%$ of the $P$. graminis subsp. graminicola pustules were infected. Virulent strains of $S$. filum can infect $98 \%$ of $M$. epitea pustules and reduce spore production by $98 \%$ (40). Our model (9) predicts that, if an S. filum isolate infected $98 \%$ of $P$. graminis subsp. graminicola pustules and reduced spore production by $98 \%$, the rust population would approach zero by spring.

S. filum has been reported as a component of several rust pathosystems even without human intervention. Naturally occurring levels of $S$. filum infection in $C$. strobilinum uredinia in North Florida oak stands was between 7 and 93\% in 1975 (16). Levels of $S$. filum-infected Melampsora spp. uredinia on willow plantations in Germany was between 15 and 26\% in 2000 to 2002 (17). A Melampsora spp. epidemic was suppressed by S. filum without application of the mycoparasite in the United Kingdom in 1990 (20). Over the winters of 2000 to 2003 , we observed naturally occurring S. filum infection levels of 2 and $25 \%$ of stem rust pustules in first- and second-year plantings, respectively, of noninoculated perennial ryegrass. S. filum was found in $43 \%$ more pustules on dead leaves than on live leaves on the second-year plantings. Although the presence of $S$. filum in these pustules on dead leaves is of little consequence with respect to rust spore production (active $P$. graminis subsp. graminicola requires living host tissue), the infected pustules could represent a reservoir of overwintering inoculum for the biocontrol fungus.

The results of these experiments provide evidence that lower $P$. graminis subsp. graminicola overwintering populations give rise to less severe epidemics in the spring, supporting earlier indications of this effect $(27,33)$. Therefore, the disease management effectiveness of treatments we tested can be assessed by their ability to produce a reduction in overwinter pathogen population. Our controlled inoculations, which established $S$. filum in emerging $P$. graminis subsp. graminicola uredinia before plants were outplanted to the field, showed that the S. filum population survived the winter on $P$. graminis subsp. graminicola uredinia. S. filum reduced the $P$. graminis subsp. graminicola pustule count through late spring at two sites during one year (2009-10). In another year, $S$. filum infected $P$. graminis subsp. graminicola uredinia in the fall but the uredinial population (whether in S. filum-inoculated treatments or not) crashed in February and, therefore, it was impossible to observe a late spring effect of $S$. filum on rust severity. We were unable to locate $S$. filum growing outside $P$. graminis subsp. graminicola uredinia and presume that the $S$. filum population also crashed in the absence of its host.

In the experiments where $S$. filum was applied monthly to plants in the field, there was a significant increase in the proportion of pustules infected in both years on the first-year stand of perennial ryegrass over the noninoculated checks. Results from the repeated observations on designated plants, as reported here, demonstrated that monthly applications of S. filum decreased the severity of the P. graminis subsp. graminicola epidemic in both years. These experiments had additional assessment methods described elsewhere (9) consisting of destructively sampled plants, as well as plants removed intact from the field for periodic observation during subsequent growth and pustule development in a glasshouse. In all cases except one of the destructive-sampling methods in one year, these observations supported the conclusion drawn in this report, that multiple applications of $S$. filum reduce overwintering and early summer stem rust populations on perennial ryegrass. In none of the experiments, as measured by any methods, did a single application of $S$. filum in the fall produce a statistically significant reduction in overwintering stem rust population.

One winter application of the fungicide Quilt significantly reduced the spring $P$. graminis subsp. graminicola population on the first-year stands. Integration of biocontrol and fungicide for disease management could be possible if the biocontrol agent is relatively insensitive to the fungicide controlling the rust pathogen. We determined in laboratory tests that $S$. filum germination and growth is inhibited by azoxystrobin (Quadris) and chlorothalanil (Bravo) fungicides on water agar plates but shows little inhibition in the presence of the propiconazole fungicide (Tilt), especially at field-

Table 1. Controlled inoculation experiment analysis ${ }^{\mathrm{x}}$

\begin{tabular}{|c|c|c|c|c|c|}
\hline \multirow[b]{3}{*}{ Year, cultivar } & \multirow[b]{3}{*}{ Treatment } & \multicolumn{4}{|c|}{ Area under the disease progress curve } \\
\hline & & \multicolumn{2}{|c|}{ Site 1} & \multicolumn{2}{|c|}{ Site 2} \\
\hline & & Pustules $^{\mathbf{y}}$ & Proportion $(\%)^{\mathrm{z}}$ & Pustules $^{y}$ & Proportion $(\%)^{\mathrm{z}}$ \\
\hline \multicolumn{6}{|l|}{ 2009-10 } \\
\hline \multirow{3}{*}{ Jet } & Control & $399 \mathrm{~b}$ & 0 & $13 \mathrm{~b}$ & $1 \mathrm{~b}$ \\
\hline & P. graminis subsp. graminicola & $1,510 \mathrm{a}$ & 0 & $1,868 \mathrm{a}$ & $3 \mathrm{~b}$ \\
\hline & Infected with $S$. filum & $521 \mathrm{~b}$ & $2 \mathrm{a}$ & $99 \mathrm{~b}$ & $11 \mathrm{a}$ \\
\hline \multirow[t]{3}{*}{ Morningstar } & Control & $\ldots$ & $\ldots$ & $2 \mathrm{~b}$ & 0 \\
\hline & P. graminis subsp. graminicola & $\ldots$ & $\ldots$ & $790 \mathrm{ab}$ & 0 \\
\hline & Infected with S. filum & $\ldots$ & $\ldots$ & $78 \mathrm{~b}$ & $1 \mathrm{~b}$ \\
\hline \multicolumn{6}{|c|}{ 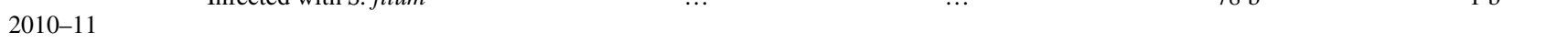 } \\
\hline \multirow[t]{3}{*}{ Jet } & Control & 0 & 0 & 0 & 0 \\
\hline & P. graminis subsp. graminicola & 0 & 0 & 0 & 0 \\
\hline & Infected with $S$. filum & 0 & $2 \mathrm{a}$ & 0 & $12 \mathrm{~b}$ \\
\hline \multirow[t]{3}{*}{ Morningstar } & Control & 0 & 0 & 0 & 0 \\
\hline & P. graminis subsp. graminicola & 0 & 0 & 0 & $2 \mathrm{c}$ \\
\hline & Infected with $S$. filum & 0 & $5 \mathrm{a}$ & 0 & $19 \mathrm{ab}$ \\
\hline \multirow[t]{3}{*}{ Linn } & Control & 0 & 0 & 0 & 0 \\
\hline & P. graminis subsp. graminicola & 0 & 0 & 0 & $5 \mathrm{c}$ \\
\hline & Infected with S. filum & 0 & $1 \mathrm{a}$ & 0 & $33 \mathrm{a}$ \\
\hline
\end{tabular}

${ }^{\mathrm{x}}$ Area under the disease progress curve (AUDPC) means and statistical analysis for the number of pustules of Puccinia graminis subsp. graminicola and the proportion of $P$. graminis subsp. graminicola pustules infected with Sphaerellopsis filum. The two fungi were inoculated under controlled conditions and plants were transplanted to sites 1 and 2 in 2 years of experiments (2009-10 and 2010-11). Data show the mean area under the disease progress curve of $P$. graminis subsp. graminicola pustules from 1 March to the end of the sampling period, and the proportion of P. graminis subsp. graminicola pustules infected with $S$. filum over the entire sampling period, on $10 \mathrm{~cm}$ of perennial ryegrass row. Significant differences between cultivar and inoculation treatments (determined by one- and two-way analysis of variance, $\alpha=0.05$ ) are denoted by different letters within a column for each year. Analysis was conducted within each site but not between sites.

y $P$. graminis subsp. graminicola pustules. Area under the disease progress curve of number of $P$. graminis subsp. graminicola pustules per $10 \mathrm{~cm}$ row versus time, from 1 March to 11 June in 2009-10 and to 2 June in 2010-11.

${ }^{\mathrm{z}}$ Proportion of $P$. graminis subsp. graminicola pustules with S. filum. Area was calculated from the proportion of $P$. graminis subsp. graminicola pustules infected with $S$. filum over the full duration of the experiment. 
rate concentrations. Propiconazole has been shown to reduce latent $P$. graminis subsp. graminicola infections and prevent future $P$. graminis subsp. graminicola infections by inhibiting rust spore germination (29). S. filum and a propiconazole fungicide may be more effective at controlling rust disease when introduced together than when introduced independently. Considerations mitigating against the practical utility of winter fungicide application are the unpredictability of the need for fungicide (the P. graminis subsp. graminicola population sometimes crashes during the winter without any intervention), and the fact that a majority of winter days in the study region are too wet to permit fungicide application.

This experiment provided further evidence that second- and third-year stands of perennial ryegrass have lower rust populations in spring and early summer than do first-year stands (27). In 2009-
10, first-year stands had 2.8 times greater $P$ graminis subsp. graminicola severity as calculated from the area under the disease progress curve from 1 March until 11 June than second-year stands across all treatments and observation methods. In 2010-11, the first-year stand had a spring $P$. graminis subsp. graminicola severity (calculated from the area under the disease progress curve from 1 March to 2 June) that was more than 300 times greater than the third-year stand. We observed that $S$. filum can infect $P$. graminis subsp. graminicola pustules in first-year field stands of perennial ryegrass during Oregon winter weather conditions, but that a greater proportion of $P$. graminis subsp. graminicola pustules (in all treatments) on the second-year plantings than the first-year plantings were infected initially. This suggests that $S$. filum might be one of the factors that reduced the $P$. graminis subsp.

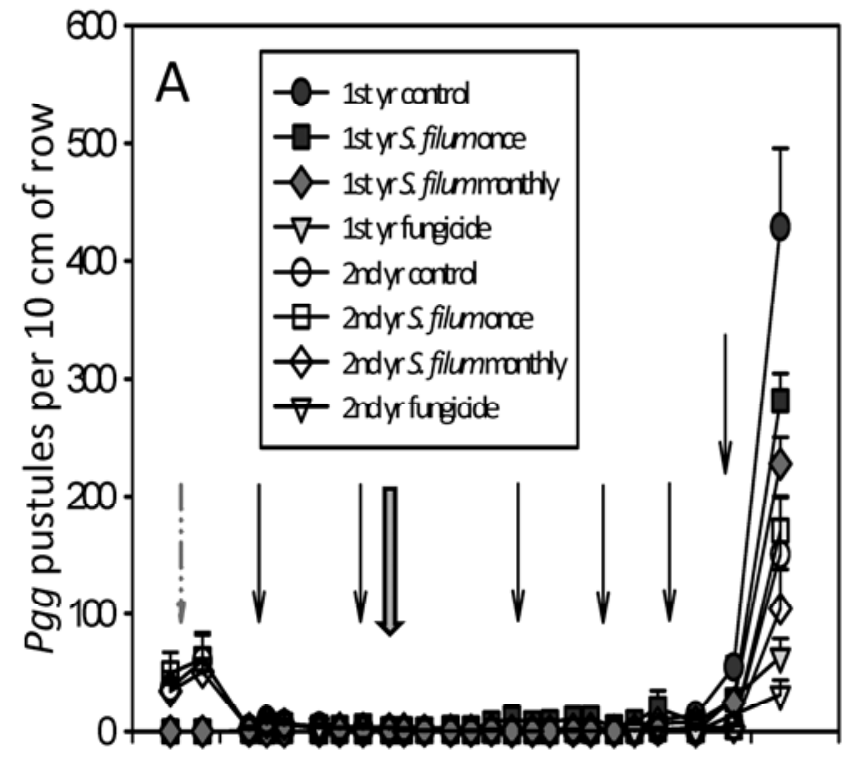

Nov Dec Jan Feb Mar Apr May Jun Jul

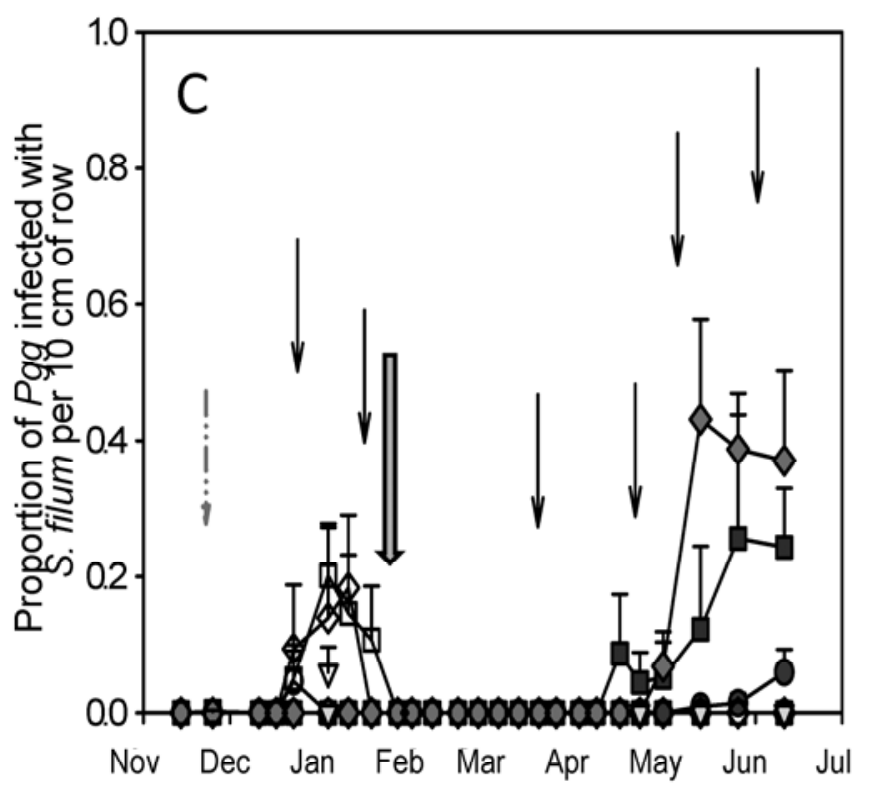

Month (2009-10)

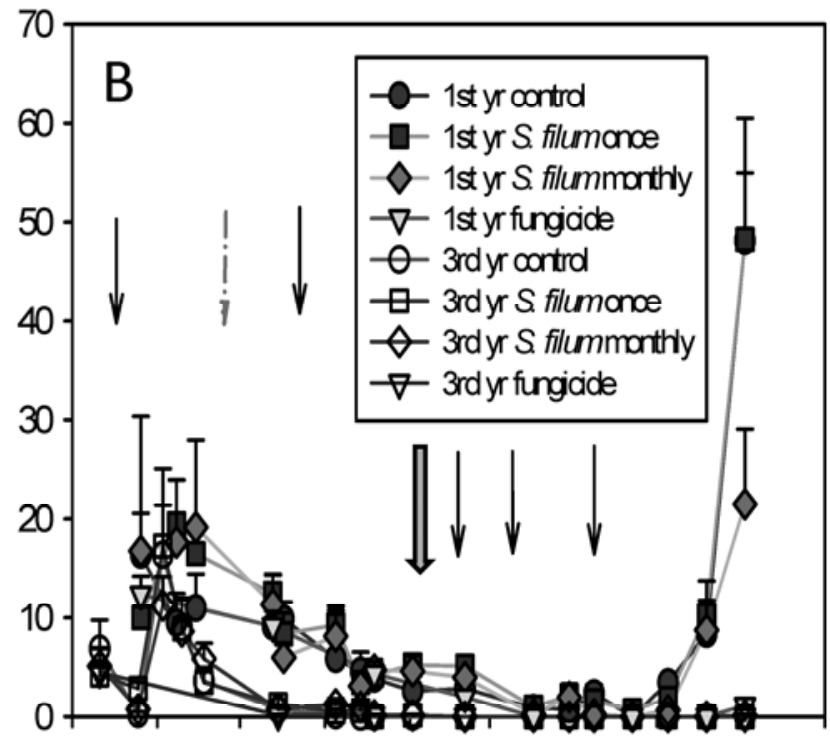

Oct Nov Dec Jan Feb Mar Apr May Jun Jul

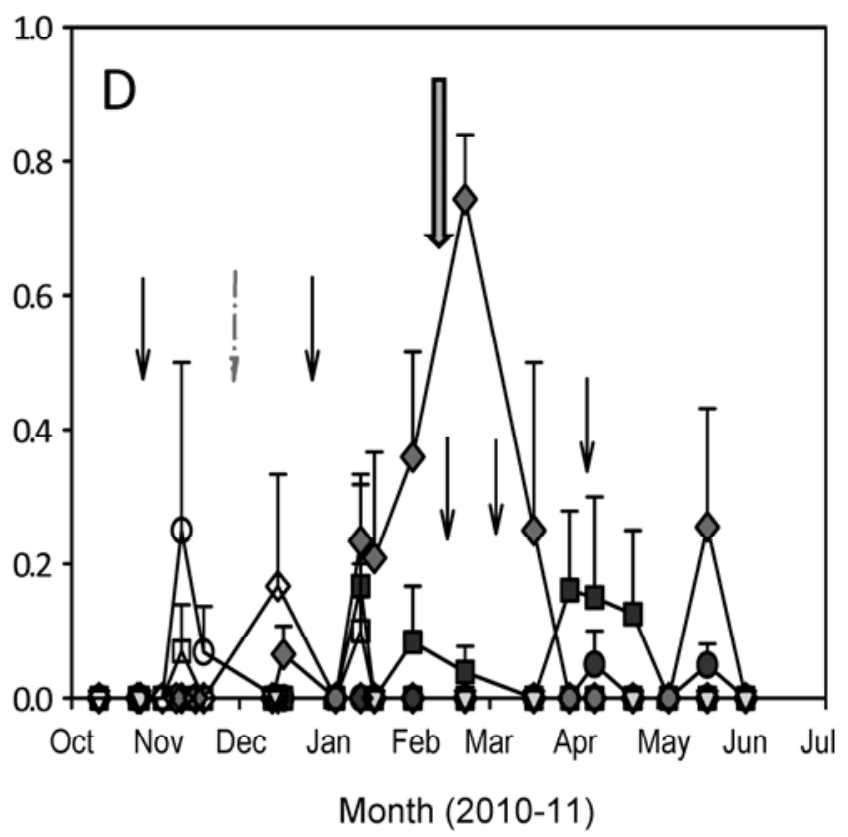

Fig. 6. Field experiment of Sphaerellopsis filum application to ryegrass naturally infected with Puccinia graminis subsp. graminicola (Pgg). A and B, Number of $P$. graminis subsp. graminicola pustules and $\mathbf{C}$ and $\mathbf{D}$, the proportion of $P$. graminis subsp. graminicola pustules infected with $S$. filum. Data were taken on $10 \mathrm{~cm}$ of row that was repeatedly observed at site 1 in $\mathbf{A}$ and $\mathbf{C}, 2009-10$ and $\mathbf{B}$ and D, 2010-11. Treatments include (i) a nontreated control, (ii) one application of $S$. filum, (iii) monthly applications of S. filum, or (iv) Quilt fungicide applied one time on newly planted (first-year) or established (second- or third-year) stands of perennial ryegrass. Application dates for the different treatments are indicated by arrows, and are listed by treatment type: (i) one $S$. filum application: thin dashed arrow, (ii) monthly $S$. filum applications: thin solid arrows, or (iii) Quilt fungicide application: thick solid arrow. Note different y-axis scales in A and B. 
Table 2. Field inoculation experiments with applications of Sphaerellopsis filum or Quilt fungicide at site 1in 2009-10 and 2010-11 ${ }^{\mathrm{v}}$

\begin{tabular}{|c|c|c|c|}
\hline \multirow[b]{2}{*}{ Year, age, effect ${ }^{w}$} & \multirow[b]{2}{*}{ Treatment $^{\mathrm{x}}$} & \multicolumn{2}{|c|}{$\begin{array}{l}\text { Area under the disease } \\
\text { progress curve }\end{array}$} \\
\hline & & Pustules $^{y}$ & Proportion $(\%)^{\mathrm{z}}$ \\
\hline \multicolumn{4}{|l|}{$2009-10$} \\
\hline 1 & Control & $4,630 \mathrm{a}$ & $2 \mathrm{~b}$ \\
\hline 1 & Once & $3,389 \mathrm{a}$ & $9 \mathrm{ab}$ \\
\hline 1 & Monthly & $2,402 \mathrm{~b}$ & $15 \mathrm{a}$ \\
\hline 1 & Fungicide & 924 bc & 0.00 \\
\hline 2 & Control & $1,285 \mathrm{bc}$ & $1 \mathrm{~b}$ \\
\hline 2 & Once & $1,463 \mathrm{bc}$ & $4 a b$ \\
\hline 2 & Monthly & $951 \mathrm{bc}$ & $4 a b$ \\
\hline 2 & Fungicide & $459 \mathrm{c}$ & $3 a b$ \\
\hline Block effect & $\ldots$ & No & No \\
\hline Interaction & $\ldots$ & Yes & No \\
\hline \multicolumn{4}{|l|}{$2010-11$} \\
\hline 1 & Control & $543 \mathrm{a}$ & $1 \mathrm{~b}$ \\
\hline 1 & Once & $564 \mathrm{a}$ & $9 \mathrm{~b}$ \\
\hline 1 & Monthly & $308 \mathrm{ab}$ & $35 \mathrm{a}$ \\
\hline 1 & Fungicide & $8 \mathrm{bc}$ & $0.0 \mathrm{~b}$ \\
\hline 3 & Control & $1 \mathrm{c}$ & $2 b$ \\
\hline 3 & Once & $0.0 \mathrm{c}$ & $2 b$ \\
\hline 3 & Monthly & $1 \mathrm{c}$ & $5 \mathrm{~b}$ \\
\hline 3 & Fungicide & 0.00 & $0.0 \mathrm{~b}$ \\
\hline Block effect & $\ldots$ & No & No \\
\hline Interaction & $\ldots$ & Yes & Yes \\
\hline
\end{tabular}

${ }^{\mathrm{v}}$ Area under the disease progress curve means and statistical analysis for Puccinia graminis subsp. graminicola pustules from 1 March to the end of the sampling period, and for the proportion of $P$. graminis subsp. graminicola pustules infected with $S$. filum over the entire sampling period are shown. Data are the mean area under the disease progress curve of $P$. graminis subsp. graminicola pustules, or the proportion of $P$. graminis subsp. graminicola pustules infected with $S$. filum, along $10 \mathrm{~cm}$ of perennial ryegrass row repeatedly observed across time (four replications). Significant differences (two-way analysis of variance, $\alpha=$ 0.05 ) are denoted by different letters within a column and a year.

${ }^{\mathrm{w}}$ Stand age in years. Block effect $=$ statistically significant effect of block and Interaction $=$ statistically significant interaction between treatment and stand age.

x Treatments are (i) a noninoculated control, (ii) one application of S. filum, (iii) monthly applications of S. filum, or (iv) Quilt fungicide applied one time in the winter.

${ }^{\text {y }}$ Number of $P$. graminis subsp. graminicola pustules. Area was calculated from $P$. graminis subsp. graminicola pustule severity from 1 March to 11 June in 2009-10 and to 2 June in 2010-11.

${ }^{\mathrm{z}}$ Proportion of $P$. graminis subsp. graminicola pustules with $S$. filum. Area was calculated from the proportion of $P$. graminis subsp. graminicola pustules infected with $S$. filum over the full duration of the experiment.

graminicola severity in the spring on the second-year stands. Spring levels of rust were not significantly different in check and $S$. filum-treated plots in second- and third-year stands. A possible reason that treatment effects were not observed in these established stands is that the $P$. graminis subsp. graminicola population crashed in late winter (February) in established plants of all treatments, including the check. Our previous observations over several years (unpublished data) show that the P. graminis subsp. graminicola population typically reaches its lowest level, in some years being visually undetectable, in February to March. The mechanism is unknown but perhaps leaves (and, therefore, their rust occupants) in the second-year stands have a shorter average lifetime than do leaves in first-year stands during the winter. Additionally, leaf tissue in older stands may be more resistant to $P$. graminis subsp. graminicola infection, or $S$. filum infections in the fall could drastically reduce the $P$. graminis subsp. graminicola population over the winter.

At our current level of knowledge, it would be difficult to implement use of $S$. filum as a conventional biofungicide. Growth in liquid culture is slow, and our current method of growing the fungus on PDA, harvesting the spores by hand, and immediately applying them under moist conditions is time intensive and impractical for large acreages. More effective control of $P$.
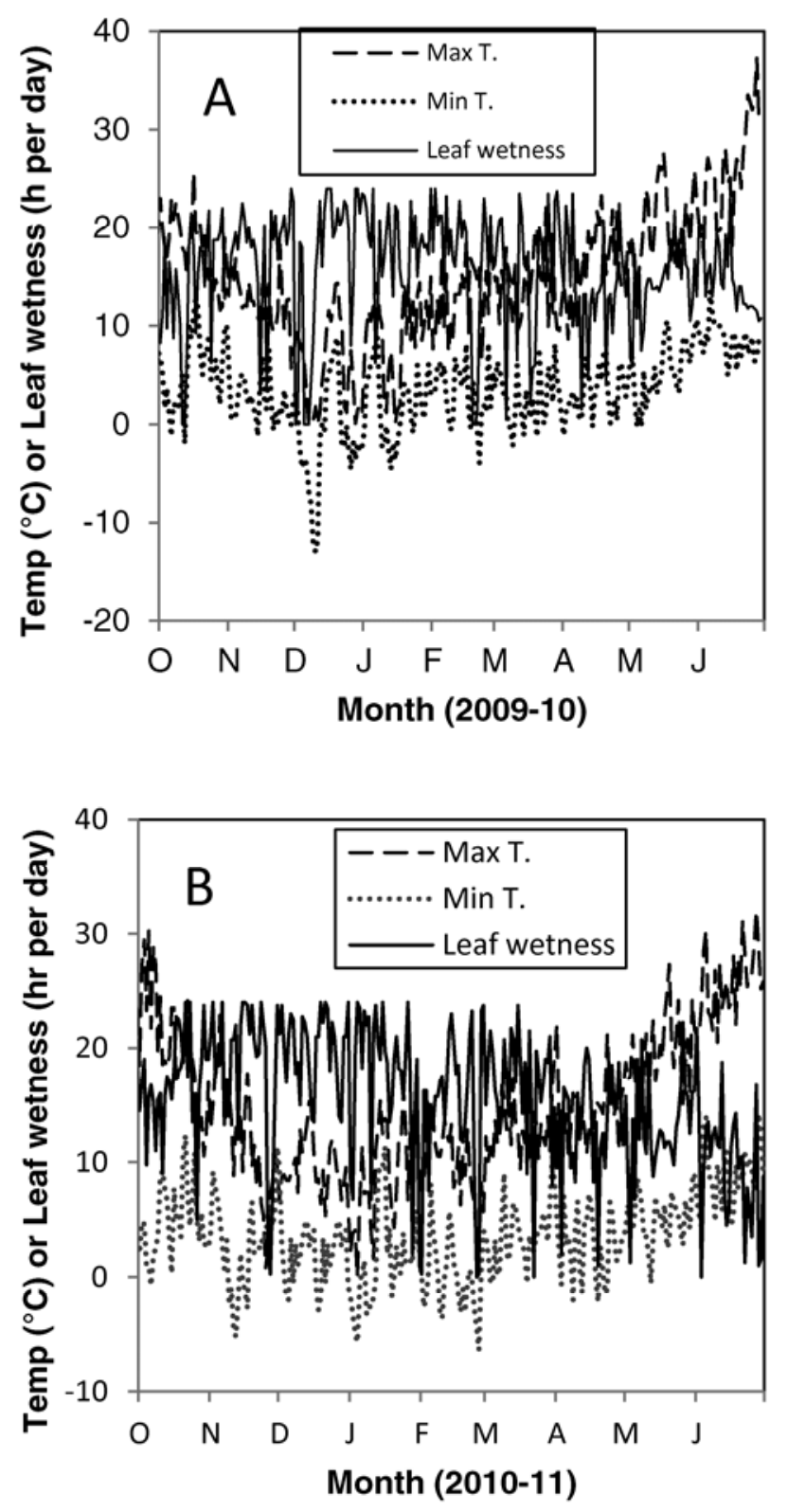

Fig. 7. Site 1 leaf wetness hours, plotted with daily high and low temperature values, for A, 2009-10 and B, 2010-11. Weather data were taken every 15 min on a data logger and analyzed for daily minimum (dotted line) and maximum (dashed line) air temperatures and hours of leaf wetness (solid line).

graminis subsp. graminicola with $S$. filum could be obtained by overcoming these current constraints. Finding more virulent strains of the fungus that can infect a greater proportion of $P$. graminis subsp. graminicola pustules and reduce the number of spores that each pustule produces could be one area to further investigate. Additionally, finding a way to apply the mycoparasite in a manner that is simple and inexpensive and insures high S. filum inoculum at optimal infection conditions would be necessary if this control tactic were to be used on a larger scale. A mycoparasite of powdery mildew (Ampelomyces quisqualis) was successfully introduced onto infected grapevines when the fungus was grown on cotton wicks saturated in malt agar (8). We observed (9) that $S$. filum can be grown on whole-grain media, and propose that such colonized grain could be applied to a field along with fertilizer applications. Increasing background levels of S. filum on rust pustules growing outside the field might also prove to be an effective means of introducing the mycoparasite. S. filum has a wide host range, and could be applied to rusts that do not infect perennial ryegrass growing near a commercial field. 


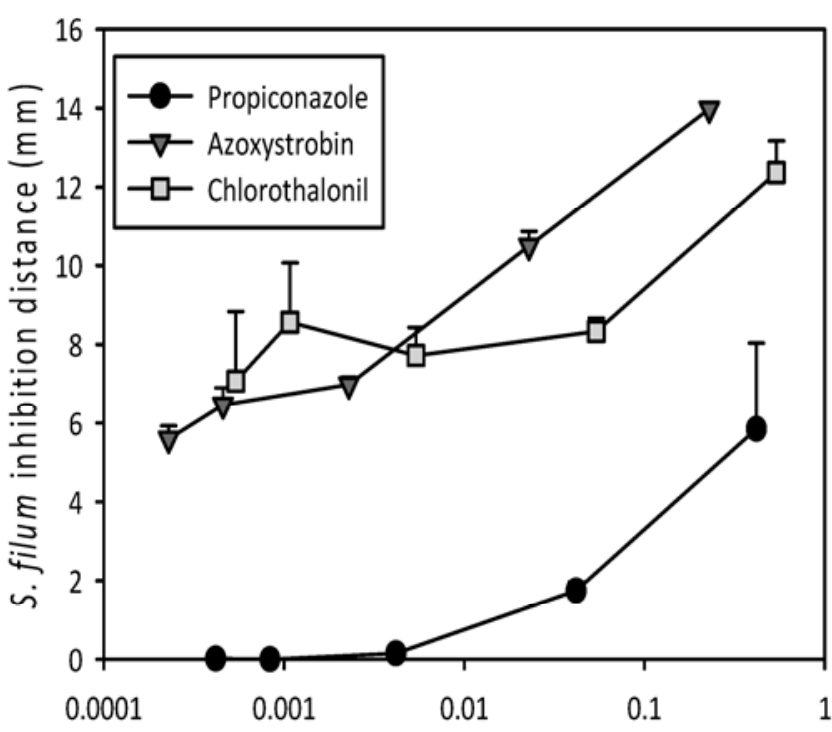

Active ingredient concentration

Fig. 8. Sphaerellopsis filum conidiospore germination inhibition distance by three fungicides. The three fungicides and their active ingredients were Tilt (propiconazole, 41.8\%), Quadris (azoxystrobin, 22.9\%), and Bravo (chlorothalonil, $54.0 \%)$. Filter discs $(5.5 \mathrm{~mm}$ in diameter) saturated in serial dilutions of each fungicide (three replications at each concentration) were placed onto water agar plates that had been sprayed with a suspension of $S$. filum conidia. Plates were incubated with 12-h dark and light periods at $23^{\circ} \mathrm{C}$ for 5 days. The distance between the edge of the filter disc and the point where there was $\geq 10 \%$ germination was measured. Data shown are the mean and standard error of the mean of two trials.

\section{Acknowledgments}

We thank S. Seguin for excellent technical assistance in several aspects of this research.

\section{Literature Cited}

1. Assante, G., Maffi, D., Saracchi, M., Farina, G., Moricca, S., and Ragazzi, A. 2004. Histological studies on the mycoparasitism of Cladosporium tenuissimum on urediniospores of Uromyces appendiculatus. Mycol. Res. 108:170-182.

2. Bayon, C., Pei, M. H., Ruiz, C., and Hunter, T. 2007. Genetic structure and spatial distribution of the mycoparasite Sphaerellopsis filum on Melampsora larici-epitea in a short-rotation coppice willow planting. Plant Pathol. 56:616-623.

3. Bolaric, S., Barth, S., Melchinger, A., and Posselt, U. 2005. Molecular genetic diversity within and among German ecotypes in comparison to European perennial ryegrass cultivars. Plant Breed. 124:257-262.

4. Calpouzos, L., Theis, T., and Rivera Batille, C. 1957. Culture of the rust parasite, Darluca filum. Phytopathology 47:108-109.

5. Carling, D., Brown, M., and Millikan, D. 1976. Ultrastructural examination of the Puccinia graminis-Darluca filum host-parasite relationship. Cytol. Histol. 66:419-422.

6. Coakley, S. M., Line, R. F., and McDaniel, L. 1988. Predicting stripe rust severity on winter wheat using an improved method for analyzing meteorological and rust data. Phytopathology 78:543-550.

7. El-Shatter, M. E.-H. 1982. Aspects of the biology of the rust mycoparasite Darluca filum. Ph.D. thesis, University of Sheffield, Sheffield, UK

8. Falk, S. P., Gadoury, D. M., Pearson, R. C., and Seem, R. C. 1995. Partial control of grape powdery mildew by the mycoparasite Ampelomycesquisqualis. Plant Dis. 79:483-490.

9. Gordon, T. 2011. Overwintering survival of stem rust on perennial ryegrass: construction of a simulation model, and effects of the mycoparasite Sphaerellopsis filum. M.S. thesis, Oregon State University, Corvallis.

10. Gowdu, B. J., and Balasubramanian, R. 1988. Role of phylloplane microorganisms in the biological control of foliar plant diseases. Z. Pflanzenkrankh. Pflanzenschutz 95:310-331.

11. Grabski, G. C., and Mendgen, K. 1985. The use of Verticillium lecanii as a biological control agent against the bean rust fungus Uromyces appendiculatus var. appendiculatus in the field and in the glasshouse. Phyto- pathol. Z. 113:243-251.

12. Hau, B., and Kranz, J. 1978. Model computations of effectiveness of hyperparasite Eudarluca caricis on rust epidemics. Z. Pflanzenkrankh. Pflanzenschutz 85:131-141.

13. Keener, P. D. 1934. Biological specialization in Darluca filum. B. Torrey Bot. Club 61:475-490.

14. Koc, N., and Defago, G. 1983. Studies on the host range of the hyperparasite Aphanocladium album. J. Phytopathol.107:214-218.

15. Kranz, J., and Brandenburger, W. 1981. An amended host list of the rust parasite Eudarluca caricis. Z. Pflanzenkrankh. Pflanzenschutz 88:682-702.

16. Kuhlman, E., Matthews, F., and Tillerson, H. 1978. Efficacy of Darluca filum for biological control of Cronartium fusiforme and $C$. strobilinum. Phytopathology 68:507-511.

17. Liesebach, M., and Zaspel, I. 2005. Biology and Genetic Diversity of the Rust Hyperparasite Sphaerellopsis filum in Central Europe. CABI, Cambridge, MA.

18. Madden, L., Hughes, G., and van den Bosch, F. 2007. The Study of Plant Disease Epidemics. American Phytopathological Society, St. Paul, MN.

19. Moschini, R., and Pérez, B. 1999. Predicting wheat leaf rust severity using planting date, genetic resistance, and weather variables. Plant Dis. 83:381384.

20. Pei, H. M., and Yuan, Z. W. 2005. Mycoparasite Sphaerellopsis filum and its potential for biological control of willow rust. Pages 243-253 in: Rust Diseases of Willow and Poplar. M. H. Pei and A. R. McCracken, eds. CABI, Cambridge, MA.

21. Pei, M. H., Hunter, T., Ruiz, C., Bayon, C., and Harris, J. 2003. Quantitative inoculation of willow rust Melampsora larici-epitea with the mycoparasite Sphaerellopsis filum (teleomorph Eudarluca caricis). Mycol. Res. 107:5763.

22. Pei, M. H., and McCracken, A. R. 2005. Rust Diseases of Willow and Poplar. CABI Publishing, Cambridge, MA.

23. Pei, M. H., Ruiz, C., Hunter, T., and Bayon, C. 2010. Interactions between Melampsora larici-epitea pathotypes and the mycoparasite Sphaerellopsis filum from willow rusts. For. Pathol. 40:33-42.

24. Pfender, W. 2009. A damage function for stem rust of perennial ryegrass seed crops. Phytopathology 99:498-505.

25. Pfender, W. F. 2001. A temperature-based model for latent period duration in stem rust of perennial ryegrass and tall fescue. Phytopathology 91:111116.

26. Pfender, W. F. 2003. Prediction of stem rust infection favorability, by means of degree-hour wetness duration, for perennial ryegrass seed crops. Phytopathology 93:467-477.

27. Pfender, W. F. 2004. Effect of autumn planting date and stand age on severity of stem rust in seed crops of perennial ryegrass. Plant Dis. 88:10171020.

28. Pfender, W. F. 2004. Role of phenology in host susceptibility and withinplant spread of stem rust during reproductive development of perennial ryegrass. Phytopathology 94:308-316.

29. Pfender, W. F. 2006. Interaction of fungicide physical modes of action and plant phenology in control of stem rust of perennial ryegrass grown for seed. Plant Dis. 90:1225-1232.

30. Plachecka, A. 2005. Microscopical observations of Sphaerellopsis filum, a parasite of Puccinia recondita. Acta Agrobot. 58:67-71.

31. Rambo, G., and Bean, G. 1970. Survival and growth of the mycoparasite Darluca filum. Phytopathology 60:1436-1440.

32. Sache, I. 1997. Effect of density and age of lesions on sporulation capacity and infection efficiency in wheat leaf rust (Puccinia recondita f. sp. tritici). Plant Pathol. 46:581-589.

33. Shaner, G., and Powelson, R. L. 1973. The oversummering and dispersal of inoculum of Puccinia striiformis in Oregon. Phytopathology 63:13-17.

34. Swendsrud, D., and Calpouzos, L. 1970. Rust uredospores increase the germination of pycnidiospores of Darluca filum. Phytopathology 60:14451447.

35. Swendsrud, D., and Calpouzos, L. 1972. Effect of inoculation sequence and humidity on infection of Puccinia recondita by the mycoparasite Darluca filum. Phytopathology 62:931-932.

36. Ward, N., Schneider, R., and Aime, M. 2011. Colonization of soybean rust sori by Simplicillium lanosoniveum. Fungal Ecol. 4:303-308.

37. Welty, R. E., and Barker, R. E. 1992. Evaluation of resistance to stem rust in perennial ryegrass grown in controlled and field conditions Plant Dis. 76:637-641.

38. Woodfield, D. 1999. Genetic improvements in New Zealand forage cultivars. Proc. N. Z. Grassland Assoc. 61:3-7.

39. Yuan, Z. W., Pei, M. H., Hunter, T., and Royle, D. J. 1998. Eudarluca caricis, the teleomorph of the mycoparasite Sphaerellopsis filum, on blackberry rust Phragmidium violaceum. Mycol. Res. 102:866-868.

40. Yuan, Z. W., Pei, M. H., Hunter, T., Ruiz, C., and Royle, D. J. 1999. Pathogenicity to willow rust, Melampsora epitea, of the mycoparasite Sphaerellopsis filum from different sources. Mycol. Res. 103:509-512. 